\title{
Status and Factors Associated with Healthcare Choices among Older Adults and Children in an Urbanized County: A Cross-Sectional Study in Kunshan, China
}

\author{
Yuxi Zhao ${ }^{1,2,3,+}{ }^{\text {, Linqi Mao }}{ }^{1,2,3,+}{ }^{\text {, Jun Lu }}{ }^{1,2,3}$, Qi Zhang ${ }^{4}$, Gang Chen ${ }^{2,3,5}$, Mei Sun ${ }^{1,2,3}$, \\ Fengshui Chang ${ }^{1,2,3}$ and Xiaohong $\mathrm{Li}^{1,2,3, *}$ \\ 1 Department of Health Policy and Management, School of Public Health, Fudan University, \\ Shanghai 200032, China; 18211020043@fudan.edu.cn (Y.Z.); maolinqi1995@163.com (L.M.); \\ lujun@shmu.edu.cn (J.L.); sunmei@fudan.edu.cn (M.S.); changfsh@fudan.edu.cn (F.C.) \\ 2 China Research Center on Disability Issues at Fudan University, Shanghai 200032, China; \\ gchen@shmu.edu.cn \\ 3 Key Laboratory of Health Technology Assessment, National Health Commission, Fudan University, \\ Shanghai 200032, China \\ 4 School of Community and Environmental Health, Old Dominion University, Norfolk, VA 23529, USA; \\ qzhang@odu.edu \\ 5 Department of Health Law and Inspection, School of Public Health, Fudan University, \\ Shanghai 200032, China \\ * Correspondence: lixh@fudan.edu.cn \\ + These authors contributed equally to this work.
}

Received: 19 September 2020; Accepted: 19 November 2020; Published: 23 November 2020

\begin{abstract}
As important unit for regional health planning, urbanized counties are facing challenges because of internal migrants and aging. This study took urbanized counties in China as cases and two key populations as objects to understand different populations' intentions of choosing corresponding health service resources and to provide support for resource allocation. A cross-sectional study was conducted in Kunshan, a highly urbanized county in China, in 2016, among older adults aged 60 or over and children aged $0-6$. Multinomial logistics models were used to identify the factors associated with healthcare choices. In this study, we found that income, distance of the tertiary provider, and migrant status were not associated with choices of tertiary healthcare outside county for children, while parents' education level was. The responsiveness of the tertiary provider inside the county was lower than primary and secondary providers inside the county, while respondents were dissatisfied with the medical technology and medical facility for the tertiary inside the county compared to those of the tertiary provider outside the county. Significant differences existed in terms of the perception of different categories of institutions. To conclude, local governments should particularly seek to strengthen pediatric primary health services and improve the responsiveness of healthcare facilities to treat geriatric and pediatric diseases, which also bring significance to the developing countries in the process of urbanization.
\end{abstract}

Keywords: healthcare choices; urbanized county; older adults; children; China

\section{Introduction}

Like most developing countries, the primary challenge of medical delivery in the Chinese health system is the gap in resource allocation across areas, as most human and material resources are concentrated in developed regions [1] with high-quality medical resources, particularly metropolises [2]. 
In addition, owing to a lack of strict gatekeeper and referral system patterns within the three-tier healthcare system [3], people embrace the freedom to choose specialized facilities directly rather than using primary health facilities. According to the regulation of health reform launched by the Chinese government in 2009, each level health provider of the three-tier healthcare system is oriented toward different populations and regions. Community health center/stations and township health center/village clinics are at the primary level, while city secondary hospitals and county hospitals are at the secondary level, and overcrowded hospitals (mainly located in urban areas) are at the tertiary level [4]. This is particularly common in economically developed big cities with high-quality health services, such as Shanghai and Beijing [5,6]. At the same time, community health centers, which are expected to serve gatekeeping roles by providing first-contact care, are underutilized $[7,8]$. This situation does not accord with the positioning of the prescribed three-tier institution, as tertiary hospitals at the city, provincial, and national levels are equipped with specialized medical resources and highly specialized medical experts. Improving the patterns of patient flow is one of the priorities of health reform launched by the Chinese government in 2009. In this regard, the county is an important unit for regional health planning. In 2015, the central government focused on establishing mechanisms for first medical visits at grassroots-level healthcare facilities, with the goal of providing care, even for serious illnesses at the county level [9].

The two-child policy took effect in China on 1 January 2016, allowing couples to have two children [10]. With the implementation of this policy, China's population is expected to reach 1.45 billion by 2030 [11], which brings a considerable demand for pediatric services. Nevertheless, due to the shortage and unavailability of pediatric resources, pediatricians are not adequately equipped to handle the baby boom. According to an estimation [12], the shortage of pediatricians in China has reached 200,000. Thus, understanding the preferences of patients is an important prerequisite for the rational allocation of medical resources. At the same time, health systems in urbanized counties are facing great challenges caused by the floating population (otherwise known as internal migrants), especially children, in addition to the universal challenges caused by population aging [13]. To inform further service developments and the creation of a more sustainable, cost-effective health system, there is an emerging need to better understand healthcare choices and examine the key associated factors: Whether the current health service system meets the health needs of certain populations and to what degree. Furthermore, the examination in this study is in the context of county-level tertiary hospitals, which differs from existing research, which have primarily focused on medical institutions [1,4].

There are numerous factors, including patient and household factors, medical provider factors, and context factors, that can be associated with healthcare choices. From the perspective of provider and context factors, a study among about 40 patients in England showed that the perception of provider responsiveness, considering factors such as convenience, waiting time, and confidence, is a strong motivating factor when choosing primary care [14]. Perceived professionally relevant factors (e.g., whether the physician is certified) $[15,16]$ and doctor's quantity also affected patients' choices [17]. In Australia, studies have demonstrated that geographical factors were associated with patients' healthcare decision-making and the use of healthcare services, while the quality of healthcare (e.g., reputation) of different hospitals might be more important [18]. Participants' sociodemographic characteristics exerted a considerable influence on their healthcare decisions. A study in Greece found that the utilization of health services was mostly determined by health status rather than socioeconomic factors like medical insurance [19]. A study conducted in 14 tertiary hospitals in Shanghai, China, showed that patients' healthcare-seeking preferences were influenced mainly by illness severity and sociodemographic characteristics, and patients who earned higher monthly incomes expressed a preference for first-class providers [20]. Based on the hypothesis that there are certain differences in the choice of healthcare providers between adults aged 60 or over and children aged $0-6$, this study took developed counties in China as cases and two key populations as objects to understand different populations' intentions of choosing corresponding health service resources and to provide support for resource allocation. 
In China's mainland, counties are defined as rural areas and the fundamental units responsible for both developing the economy and providing health services [21]. Counties are the basic unit for regional health planning, and with the improvement of the capacity of many hospitals in highly urbanized counties, they have been further upgraded to level-three hospitals [22] responsible for undertaking the diagnosis and treatment of common and frequently occurring diseases [23]. Thus, we selected Kunshan country, the most highly urbanized county in mainland China, to study people's choices of healthcare provider types and the associated factors. As older adults and young children are the most vulnerable [24], we focused on healthcare-seeking patterns in these populations. Therefore, the aims of this study were to: (1) Describe and compare the choices of healthcare providers between older adults and young children; (2) Analyze the factors associated with healthcare decisions from three aspects: Choice of the highest (tertiary) healthcare providers outside county, choice of tertiary healthcare providers within county, and the perception-mainly based on responsiveness and the evaluation of medical-related items-among older adults and children.

\section{Materials and Methods}

\subsection{Study Design and Setting}

This was a cross-sectional study conducted in Kunshan County from June to August 2016. Kunshan County, closed to Shanghai and located in Suzhou City in the southeastern part of the Jiangsu Province, has topped the list of "Best Counties in China's Mainland" by Forbes China from 2008 to 2014. Kunshan County has a total area of 928 square kilometers. The poverty line was yuan 7500 in 2016 [25]. Based on government statistics, the annual per capita gross domestic product (GDP) in Jiangsu was yuan 107,189 in 2017, placing the area fifth among 31 provinces in China (National Bureau of Statistics, 2017). The per capita GDP of Kunshan in 2017 was about yuan 212,100, while that of the whole mainland was yuan 59,660. By the end of 2015, the population in Kunshan was 1.69 million: 0.79 million local residents with Kunshan hukou and 0.90 million internal migrants without Kunshan hukou (also called floating people, having lived in Kunshan for more than 6 months). Of these, there were nearly 111,000 children aged $0-6$ and 160,000 residents aged 60 or over. In this study, children aged 0-6 and older adults aged 60 or over formed the target population, and migrant residents refer to those who had migrated to Kunshan County and lived in Kunshan for at least 6 months (or from birth).

There are 2.55 medical practitioners per 1000 population in Kunshan [26], lower than 3.80 per 1000 population in Shanghai [27]. The number of pediatric medical practitioners was 112,800 in 2017 in China, accounting for only $3.9 \%$ of all medical practitioners [12]. There were 1.45 pediatricians per 1000 children <14 years in Shanghai [27], 1.55 per 1000 in Kunshan [26], and 0.49 per 1000 in underdeveloped counties in China [28]. There were 0.53 pediatricians per 1000 children $<14$ years at the national level [29], lower than the standard of 1.46 pediatricians in America [30]. In terms of the education level of health workers, about $43 \%$ doctors had college-level education or greater in Kunshan [26], the proportion in Shanghai was 37\% [31].

This study was conducted after obtaining ethical approval (IRB\#2015-TYSQ-03-11) from the Medical Research Ethics Committee, School of Public Health, Fudan University (IRB00002408 \& FWA00002399). Completion of the survey was considered indicative of providing informed consent to participate.

\subsection{Sampling}

The participants were selected through a multistage stratified sampling framework. In the first stage, all 11 towns in Kunshan were divided into three tiers: Center, middle, and outer surroundings of the county. Then, three towns (KF, ZP, and JX) from the three tiers were identified as the research sites. 
During the second stage, we used the simple random sampling formula, mentioned below, to calculate the sample size, where $\delta=0.05, \mathrm{u}=1.96$, and $\alpha=0.05$ :

$$
\mathrm{n}=\frac{\mathrm{u}_{\frac{a}{2}}^{2} \pi(\vdash \pi)}{\delta^{2}}
$$

Table 1. Sociodemographic characteristics of older adults and children (\%).

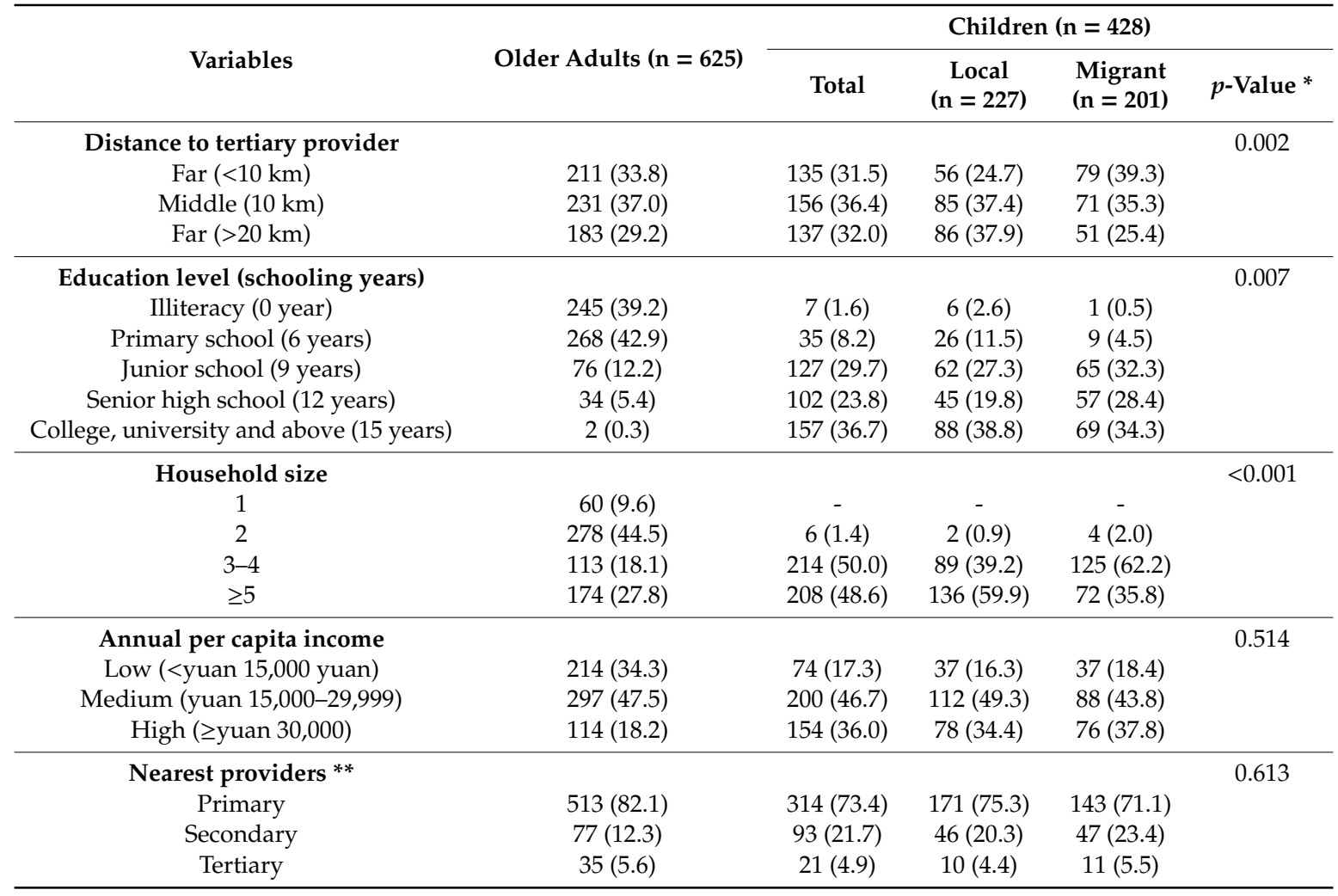

* Differences in variables between local children and migrant children. ${ }^{* *}$ Nearest providers: The type of nearest provider for respondents in Kunshan.

Table 2. Choices of healthcare providers among older adults and children.

\begin{tabular}{|c|c|c|c|c|c|c|c|}
\hline \multirow{3}{*}{ Variables } & \multicolumn{6}{|c|}{ Condition } & \multirow{3}{*}{$p$-Value ** } \\
\hline & \multicolumn{2}{|c|}{ Minor } & \multicolumn{2}{|c|}{ Somewhat } & \multicolumn{2}{|c|}{ Serious } & \\
\hline & $\mathbf{N}$ & $\%$ & $\mathbf{N}$ & $\%$ & $\mathbf{N}$ & $\%$ & \\
\hline \multicolumn{8}{|l|}{ Older adults $(n=625)$} \\
\hline Primary facilities inside the county & 463 & 74.08 & 175 & 28.00 & 56 & 8.96 & \\
\hline Secondary facilities inside the county & 96 & 15.36 & 114 & 18.24 & 61 & 9.76 & \\
\hline Tertiary facilities inside the county & 58 & 9.28 & 318 & 50.88 & 386 & 61.76 & $<0.001$ \\
\hline Secondary outside the county & 3 & 0.48 & 1 & 0.16 & 2 & 0.32 & \\
\hline Tertiary facilities outside the county & 5 & 0.80 & 17 & 2.72 & 120 & 19.20 & \\
\hline \multicolumn{8}{|l|}{ Children $(n=428)$} \\
\hline Primary facilities inside the county & 265 & 61.92 & 96 & 22.43 & 25 & 5.84 & \\
\hline Secondary facilities inside the county & 97 & 22.66 & 53 & 12.38 & 22 & 5.14 & \\
\hline Tertiary facilities inside the county & 57 & 13.32 & 242 & 56.54 & 247 & 57.71 & $<0.001$ \\
\hline Secondary outside the county & 0 & 0.00 & 1 & 0.24 & 2 & 0.47 & \\
\hline Tertiary facilities outside the county & 9 & 2.10 & 36 & 8.41 & 132 & 30.84 & \\
\hline$p$-value * & \multicolumn{2}{|c|}{$<0.001$} & \multicolumn{2}{|c|}{$<0.001$} & \multicolumn{2}{|c|}{$<0.001$} & \\
\hline
\end{tabular}

* Differences in choices of healthcare providers between two groups at different condition. ** According to each group, differences in choices of healthcare providers at different condition. 
Supposing that the proportion of choosing tertiary healthcare providers is 50\% [32], we obtained a sample size of about 400 older adults and children, respectively. Finally, at the health service centers in the three selected communities, based on physical examinations for older adults, 650 older adults were queried about their choices in seeking healthcare and 625 completed the questionnaires, yielding a response rate of $96.15 \%$. Based on the planned immunizations for children, 450 parents were surveyed and 428 completed the questionnaires, yielding a response rate of $95.20 \%$.

Table 3. Multinomial logit estimates on choices of healthcare providers among older adults.

\begin{tabular}{|c|c|c|c|c|c|c|}
\hline \multirow{3}{*}{ Characteristics } & \multicolumn{6}{|c|}{ Older Adults $(n=625)$} \\
\hline & \multicolumn{2}{|c|}{ Minor Illness } & \multicolumn{2}{|c|}{ Somewhat Illness } & \multicolumn{2}{|c|}{ Serious Illness } \\
\hline & OR $(95 \% C I)$ & $p$-Value & OR $(95 \% C I)$ & $p$-Value & OR $(95 \% C I)$ & $p$-Value \\
\hline & \multicolumn{6}{|c|}{ Category 1 vs. Category 2 (base) * } \\
\hline Age & $1.010(0.962,1.060)$ & 0.690 & $1.007(0.982,1.032)$ & 0.594 & $1.007(0.977,1.038)$ & 0.646 \\
\hline Gender & $0.663(0.325,1.353)$ & 0.259 & $1.009(0.693,1.470)$ & 0.962 & $0.958(0.607,1.512)$ & 0.854 \\
\hline Education & $0.600(0.412,0.875)$ & 0.008 & $0.645(0.512,0.814)$ & $<0.001$ & $0.859(0.645,1.145)$ & 0.301 \\
\hline Chronic diseases & $0.947(0.473,1.894)$ & 0.877 & $0.998(0.699,1.426)$ & 0.993 & $0.887(0.575,1.368)$ & 0.588 \\
\hline Annual per capita income & $0.912(0.578,1.437)$ & 0.690 & $0.912(0.710,1.173)$ & 0.473 & $1.047(0.770,1.424)$ & 0.771 \\
\hline \multicolumn{7}{|l|}{ Household size (Ref: $\leq 4)$} \\
\hline$\geq 5$ & $0.600(0.297,1.214)$ & 0.155 & $0.707(0.475,1.053)$ & 0.088 & $0.697(0.417,1.165)$ & 0.168 \\
\hline \multicolumn{7}{|l|}{$\begin{array}{l}\text { Nearest providers } \\
\text { (Ref: not tertiary) }\end{array}$} \\
\hline Tertiary & $0.026(0.011,0.065)$ & $<0.001$ & $0.149(0.044,0.508)$ & 0.002 & $0.185(0.024,1.421)$ & 0.105 \\
\hline \multicolumn{7}{|l|}{$\begin{array}{l}\text { Distance to tertiary } \\
\quad(\text { Ref: }<10 \mathrm{~km})\end{array}$} \\
\hline Middle (10-km) & $0.848(0.417,1.722)$ & 0.648 & $2.279(1.500,3.462)$ & $<0.001$ & $1.039(0.624,1.732)$ & 0.883 \\
\hline \multirow[t]{2}{*}{$\operatorname{Far}(>20 \mathrm{~km})$} & $3.838(1.042,14.133)$ & 0.043 & $3.874(2.430,6.178)$ & $<0.001$ & $0.872(0.498,1.527)$ & 0.631 \\
\hline & \multicolumn{6}{|c|}{ Category 3 vs. Category 2 (base) * } \\
\hline Age & $1.057(0.924,1.210)$ & 0.417 & $1.014(0.941,1.094)$ & 0.708 & $1.004(0.972,1.036)$ & 0.815 \\
\hline Gender & $0.210(0.018,2.468)$ & 0.214 & $0.822(0.267,2.532)$ & 0.733 & $1.071(0.675,1.701)$ & 0.770 \\
\hline Education & $0.908(0.282,2.930)$ & 0.872 & $1.983(1.060,3.710)$ & 0.032 & $1.450(1.23,1.871)$ & 0.004 \\
\hline Chronic diseases & $2.500(0.245,25.544)$ & 0.440 & $1.292(0.696,2.395)$ & 0.417 & $0.846(0.544,1.315)$ & 0.456 \\
\hline Annual per capita income & $0.865(0.238,3.139)$ & 0.825 & $0.953(0.468,1.940)$ & 0.895 & $1.392(1.028,1.885)$ & 0.032 \\
\hline \multicolumn{7}{|l|}{ Household size (Ref: $\leq 4$ ) } \\
\hline$\geq 5$ & $0.504(0.048,5.266)$ & 0.567 & $0.968(0.318,2.947)$ & 0.954 & $1.170(0.731,1.874)$ & 0.512 \\
\hline \multicolumn{7}{|l|}{$\begin{array}{l}\text { Nearest providers } \\
\text { (Ref: Not tertiary) }\end{array}$} \\
\hline Tertiary & $0.423(0.036,5.012)$ & 0.495 & $1.963(0.394,9.780)$ & 0.411 & $2.908(1.387,6.095)$ & 0.005 \\
\hline \multicolumn{7}{|l|}{$\begin{array}{l}\text { Distance to tertiary } \\
(\text { Ref: }<10 \mathrm{~km})\end{array}$} \\
\hline Middle (10-km) & $1.196(0.13010 .971)$ & 0.874 & $1.694(0.486,5.908)$ & 0.408 & $0.842(0.513,1.384)$ & 0.498 \\
\hline $\operatorname{Far}(>20 \mathrm{~km})$ & $3.105(0.163,59.325)$ & 0.452 & $3.555(0.917,13.785)$ & 0.067 & $0.638(0.352,1.156)$ & 0.139 \\
\hline
\end{tabular}

\subsection{Data Collection and Instruments}

The survey was organized by the local Health Bureau in Kunshan in 2016. The investigators included teachers and graduate and undergraduate students from Fudan University, all of whom received formal training before the investigation.

The investigation items in this study were extracted from the "An Analysis Report of National Health Services Survey in China questionnaire" [33], the validity and reliability of which have previously been demonstrated [34]. In this study, six experts were invited to conduct the validity assessment. Prior to the formal survey, 51 participants (not included in the main analysis) were recruited for a preliminary investigation.

We conducted face-to-face interviews using a structured questionnaire based on the family unit (when the respondents were children, the children's parents answered the questions). In terms of each family member, the main contents included basic individual characteristics such as age, gender, occupation, migrant status, education, medical insurance, and hospitalization. In terms of family information, the participants were asked about: (1) Basic family-level information, such as household size and annual income; (2) Their choices of different health facilities when older adults or young children were faced with three different degrees of illness: minor illness, an illness of unclear severity 
(somewhat serious), and serious illness. Minor illness included a common, frequently occurring ailment, such as a cold, cough, or chronic illness. Referring to "An Analysis Report of National Health Services Survey in China questionnaire," serious sickness involved serious and unpleasant symptoms (e.g., sustained high fevers with breathing difficulties, chest pain, severe headache), while somewhat serious illness referred to chronic disease (e.g., diabetes). We first asked about choices of healthcare inside or outside the county. Then, we further inquired about the level of the facility (primary, secondary, or tertiary); (3) The participants who had medical services utilization or accompanying experience of outpatient (in 6 months) or inpatient services (in 1 year) responded to the responsiveness module of the World Health Survey (WHS) questionnaire and their evaluation of medical-related items (Cronbach's $\alpha=0.84$ ).

Table 4. Multinomial logit estimates on choices of healthcare providers among children.

\begin{tabular}{|c|c|c|c|c|c|c|}
\hline \multirow{3}{*}{ Characteristics } & \multicolumn{6}{|c|}{ Children $(n=428)$} \\
\hline & \multicolumn{2}{|c|}{ Minor Illness } & \multicolumn{2}{|c|}{ Somewhat Illness } & \multicolumn{2}{|c|}{ Serious Illness } \\
\hline & OR $(95 \% C I)$ & $p$-Value & OR $(95 \% C I)$ & $p$-Value & OR $(95 \% C I)$ & $p$-Value \\
\hline & \multicolumn{6}{|c|}{ Category 1 vs. Category 2 (base) * } \\
\hline Age & $1.151(0.930,1.426)$ & 0.197 & $1.212(1.040,1.412)$ & 0.014 & $1.323(1.051,1.664)$ & 0.017 \\
\hline \multicolumn{7}{|l|}{ Migrant (Ref: Not migrant) } \\
\hline Migrant & $1.781(0.945,3.357)$ & 0.074 & $1.195(0.752,1.898)$ & 0.452 & $1.550(0.758,3.169)$ & 0.230 \\
\hline $\begin{array}{l}\text { Annual per capita income } \\
\text { Household size (Ref: } \leq 4)\end{array}$ & $0.623(0.397,0.979)$ & 0.040 & $0.713(0.522,0.974)$ & 0.033 & $0.638(0.398,1.024)$ & 0.063 \\
\hline$\geq 5$ & $0.744(0.403,1.373)$ & 0.344 & $1.050(0.665,1.657)$ & 0.835 & $1.390(0.690,2.800)$ & 0.357 \\
\hline \multicolumn{7}{|l|}{$\begin{array}{l}\text { Nearest providers } \\
\text { (Ref: Not tertiary) }\end{array}$} \\
\hline Tertiary & $0.274(0.101,0.748)$ & 0.012 & $0.421(0.135,1.320)$ & 0.138 & $0.476(0.059,3.848)$ & 0.486 \\
\hline Parents' age & $1.041(1.000,1.083)$ & 0.046 & $1.017(0.991,1.044)$ & 0.212 & $0.992(0.955,1.031)$ & 0.692 \\
\hline \multirow[t]{2}{*}{ Parents' education } & $1.115(0.804,1.547)$ & 0.514 & $1.028(0.812,1.302)$ & 0.818 & $0.800(0.561,1.141)$ & 0.218 \\
\hline & \multicolumn{6}{|c|}{ Category 3 vs. Category 2 (base) * } \\
\hline Age & $1.064(0.597,1.900)$ & 0.832 & $1.057(0.816,1.369)$ & 0.676 & $1.109(0.947,1.300)$ & 0.200 \\
\hline \multicolumn{7}{|l|}{ Migrant (Ref: Not migrant) } \\
\hline Migrant & $4.185(0.827,21.168)$ & 0.083 & $1.541(0.722,3.290)$ & 0.263 & $1.010(0.631,1.619)$ & 0.966 \\
\hline $\begin{array}{l}\text { Annual per capita income } \\
\text { Household size (Ref: } \leq 4)\end{array}$ & $6.697(0.823,54.470)$ & 0.075 & $1.505(0.858,2.642)$ & 0.154 & $1.254(0.903,1.743)$ & 0.177 \\
\hline$\geq 5$ & $0.265(0.045,1.571)$ & 0.144 & $1.426(0.674,3.018)$ & 0.353 & $1.582(0.992,2.522)$ & 0.054 \\
\hline \multicolumn{7}{|l|}{$\begin{array}{l}\text { Nearest providers } \\
\text { (Ref: Not tertiary) }\end{array}$} \\
\hline Tertiary & $1.178(0.110,12.609)$ & 0.892 & $0.862(0.185,4.017)$ & 0.850 & $1.492(0.582,3.826)$ & 0.405 \\
\hline Parents' age & $1.113(1.007,1.231)$ & 0.036 & $1.032(0.986,1.081)$ & 0.180 & $1.023(0.994,1.052)$ & 0.116 \\
\hline Parents' education & $1.614(0.628,4.152)$ & 0.320 & $1.415(0.925,2.165)$ & 0.109 & $1.500(1.160,1.941)$ & 0.002 \\
\hline
\end{tabular}

* category 1: Primary and secondary facilities inside the county; category 2: Tertiary facilities inside the county; category 3: Tertiary facilities outside the county.

\subsection{Statistical Analysis}

Double data entry was independently completed by two trained college students using EpiData 3.1 (EpiData Association, Denmark, Odense). Data analysis was performed with STATA 14.0 (Stata Corporation, College Station, TX, USA). Descriptive statistics and the $\chi^{\wedge} 2$ test were used to describe the sociodemographic characteristics of the older adults and children (Table 1) and differences between the healthcare choices of two groups (Table 2). We used a multinomial logistic model to identify the factors associated with choices of healthcare providers among older adults and children (Tables 3 and 4). The dependent variables were different type of chosen hospitals inside and outside county, coded as: (i) Primary and secondary facilities inside the county, (ii) tertiary facilities inside the county, and (iii) tertiary facilities outside the county. The independent variables included annual per capita income, household size, nearest healthcare providers in Kunshan, migrant status, age, education, town, chronic diseases, and parents' age and education. One-way ANOVA, for univariate analysis, was used to compare perception of different providers (Table 5). The overall test of relationship showed that the probability of the model was $0.0003(<0.05$, therefore significant). Odds 
ratios (OR) were calculated with 95\% confidence intervals (CI). Statistical significance was defined as $p$-value $<0.05$.

Table 5. Comparing the perception of healthcare services among older adults and children.

\begin{tabular}{|c|c|c|c|c|c|c|c|}
\hline \multirow[b]{2}{*}{ Theme } & \multirow[b]{2}{*}{ cat.1 } & \multirow[b]{2}{*}{ cat.2 } & \multirow[b]{2}{*}{ cat.3 } & \multirow[b]{2}{*}{$p$-Value } & \multicolumn{3}{|c|}{$p$-Value } \\
\hline & & & & & $\begin{array}{l}\text { cat.1 vs. } \\
\text { cat. } 2\end{array}$ & $\begin{array}{l}\text { cat. } 1 \text { vs. } \\
\text { cat. } 3\end{array}$ & $\begin{array}{l}\text { cat. } 2 \text { vs. } \\
\text { cat. } 3\end{array}$ \\
\hline & \multicolumn{7}{|c|}{ Older adults $(n=625)$} \\
\hline Responsiveness & & & & & & & \\
\hline Communication & 4.286 & 3.974 & 3.905 & $<0.001$ & $<0.001$ & $<0.001$ & 0.387 \\
\hline Autonomy & 4.286 & 3.965 & 3.905 & $<0.001$ & $<0.001$ & $<0.001$ & 0.511 \\
\hline Confidentiality & 4.494 & 4.299 & 4.270 & $<0.001$ & $<0.001$ & 0.001 & 0.954 \\
\hline Prompt attention (traveling) & 4.682 & 4.465 & 4.143 & $<0.001$ & $<0.001$ & $<0.001$ & 0.007 \\
\hline Prompt attention (waiting) & 4.136 & 4.090 & 3.762 & $<0.001$ & 0.559 & 0.001 & 0.006 \\
\hline Dignity & 4.494 & 4.297 & 4.254 & $<0.001$ & $<0.001$ & 0.001 & 0.892 \\
\hline Choice & 4.023 & 3.936 & 3.714 & $<0.001$ & 0.005 & 0.050 & 0.229 \\
\hline $\begin{array}{c}\text { Quality of basic amenities } \\
\text { Others }\end{array}$ & 4.042 & 4.032 & 3.819 & $<0.001$ & 0.965 & 0.175 & 0.205 \\
\hline Medical technology & 3.815 & 3.968 & 4.191 & $<0.001$ & $<0.001$ & $<0.001$ & $<0.001$ \\
\hline Medical facility & 3.920 & 4.035 & 4.206 & $<0.001$ & 0.002 & $<0.001$ & 0.009 \\
\hline Medical charges & 3.815 & 3.776 & 3.794 & 0.767 & 0.857 & 0.992 & 0.996 \\
\hline \multirow[t]{2}{*}{ Medicine } & 3.686 & 3.968 & 4.095 & $<0.001$ & $<0.001$ & $<0.001$ & 0.023 \\
\hline & \multicolumn{7}{|c|}{ Children $(n=428)$} \\
\hline Responsiveness & & & & & & & \\
\hline Communication & 4.371 & 3.982 & 3.899 & $<0.001$ & $<0.001$ & $<0.001$ & 0.268 \\
\hline Autonomy & 4.362 & 3.977 & 3.928 & $<0.001$ & $<0.001$ & $<0.001$ & 0.635 \\
\hline Confidentiality & 4.491 & 4.398 & 4.362 & 0.107 & 0.221 & 0.230 & 0.953 \\
\hline Prompt attention (traveling) & 4.647 & 4.519 & 4.348 & $<0.001$ & 0.019 & 0.002 & 0.130 \\
\hline Prompt attention (waiting) & 4.069 & 4.153 & 3.812 & $<0.001$ & 0.086 & 0.002 & 0.000 \\
\hline Dignity & 4.491 & 4.407 & 4.377 & 0.175 & 0.323 & 0.307 & 0.967 \\
\hline Choice & 3.966 & 3.982 & 4.058 & 0.361 & 0.974 & 0.601 & 0.730 \\
\hline $\begin{array}{c}\text { Quality of basic amenities } \\
\text { Others }\end{array}$ & 3.966 & 3.982 & 4.058 & 0.361 & 0.974 & 0.601 & 0.730 \\
\hline Medical technology & 3.565 & 4.000 & 4.362 & $<0.001$ & $<0.001$ & $<0.001$ & $<0.001$ \\
\hline Medical facility & 3.707 & 4.000 & 4.275 & $<0.001$ & $<0.001$ & $<0.001$ & 0.001 \\
\hline Medical charges & 3.853 & 3.829 & 3.628 & 0.089 & 0.979 & 0.043 & 0.142 \\
\hline Medicine & 3.582 & 4.120 & 4.188 & $<0.001$ & $<0.001$ & $<0.001$ & 0.613 \\
\hline
\end{tabular}

cat.1: Primary and secondary facilities inside the county; cat.2: Tertiary facilities inside the county; cat.3: Tertiary facilities outside the county.

\section{Results}

\subsection{Description of the Sample}

Table 1 displays the sociodemographic characteristics of the surveyed older adults and children. Of all the participants, there were 625 older adults and 428 children, and nearly half of the children were migrants. Approximately $43 \%$ of older adults had primary school education, and 37\% of children's families had university-level education. Nearly half of the population had a medium level annual income. For most participants, the nearest provider was a primary facility.

\subsection{Comparison of the Two Groups' Healthcare Choices}

As shown in Table 2, when the disease was serious, 30.84\% of children chose tertiary healthcare facilities outside the county, which was much higher than older adults (19.20\%). There was significant difference between choices of different healthcare providers at different conditions.

\subsection{Multinomial Logit Estimates on Choices of Healthcare Providers among Older Adults}

As depicted in Table 3, the significant factors were education level (OR $=0.600, p=0.008)$, the type of nearest facility $(\mathrm{OR}=0.149, p=0.002)$, and the distance from the tertiary facility $(\mathrm{OR}=3.874, p=0.000)$ 
in the situation of minor or somewhat illness. As for tertiary facilities outside the county, when the nearest provider was tertiary ( $\mathrm{OR}=2.908, p=0.005)$, older adults having higher education level $(\mathrm{OR}=1.450, p=0.004)$ were more likely to choose the tertiary healthcare when facing serious illness.

\subsection{Multinomial Logit Estimates on Choices of Healthcare Providers among Children}

As depicted in Table 4, when experiencing a minor illness, families near the tertiary provider were less likely to prefer primary facilities inside the county $(\mathrm{OR}=0.274, p=0.012)$. Families with higher education level were more likely to choose tertiary providers outside the county when dealing with serious illness ( $\mathrm{OR}=1.500, p=0.002)$. However, annual per capita income, the distance of the tertiary provider, and migrant status were not influencing factors in the choice of tertiary healthcare outside the county for children.

\subsection{Comparing the Perception of Healthcare Services among Older Adults and Children}

Table 5 shows the perception of health responsiveness and other medical items among older adults and children. The best-performing factors among health responsiveness inside the county were confidentiality and prompt attention (traveling) in both older adults and children. Both older adults and children indicated that the responsiveness of the tertiary provider was lower than primary and secondary providers inside the county, while both groups were dissatisfied with the medical technology and medical facility of the tertiary inside the county compared those of the tertiary outside the county.

\section{Discussion}

This is the first study in an urbanized county in China to examine the choices of healthcare providers inside and outside the county and the factors associated with those choices using a multinomial logistic model. In this study, nearly half of the young children were internal migrants, which proves that seeking healthcare is a great challenge among the floating population in China, especially for children. The survey data show that majority of older adults over 60 were non-migrants.

Older adults and young children are prioritized in China's policy for basic public health services [6]. Compared with studies in other counties [35,36], the residents of Kunshan appeared to favor internal facilities to a greater degree. Kunshan has experienced high-speed urbanization, in the wake of which there have been sufficient resources for facility improvement. Primary facilities received more investment, while two secondary facilities were upgraded to tertiary hospitals. Owing to the strength of these local facilities, increasing numbers of patients have chosen to stay in the county for their healthcare needs. However, when we focused on the target population, differences in choices of healthcare facilities became clear. Compared with older adults $(19.2 \%), 30.84 \%$ parents were more likely to prefer the highest-level healthcare resources outside the county when facing serious disease severity. This result is consistent with Zhou's study [37]. Parents' concern about their children's health makes them prioritize high-level hospitals outside the county when economic conditions permit. Another important reason may be the lack of well-trained pediatricians in local healthcare facilities, even in tertiary hospitals inside the county. We may interpret these data to indicate that the perceived inability of health providers to address severe diseases pushes residents to seek healthcare from facilities outside the county. Older adults, on the contrary, may prefer primary healthcare facilities because of chronic diseases.

Our results showed that disease severity was associated with the choice of healthcare facility, regardless of whether the population in question consisted of older adults or children. The differences in the factors associated with this choice in the two groups were apparent. In general, we found that while healthcare choices were mainly associated with sociodemographic characteristics, the type of health provider available was also an important factor. For older adults, the nearest provider type was significantly associated with healthcare choices, while for children, parental education level was an 
important factor. With regard to choosing local facilities, the correlations were more complex with various degrees of illness. The proximity of healthcare providers was important for older adults.

Nearest provider type, education level, and illness severity were significantly associated with healthcare choices in older adults. It is interesting to note that when older adults were seriously ill, they were more likely to choose a facility outside Kunshan if the nearest provider within the county was a tertiary facility. We may interpret this as indicating that households near higher-level facilities frequently sought healthcare there for minor ailments, owing to their deep mistrust in these facilities' ability to address more serious illnesses. This study also showed the family factors in older adults' choices of health facilities. A longer distance to the nearest facility was associated with a lower likelihood of choosing higher-level facilities in the case of a minor or somewhat illness. The possible reason was that, when only slightly sick, older adults could visit health facilities independently. However, when seriously ill, they would choose higher facilities, considering the close relationship between patients and their relatives in China [38].

In this study, nearly half of the young children were internal migrants. The interplay of better economic conditions, lack of health insurance for children, and lack of trust in the quality of facilities in Kunshan led parents to seek healthcare outside the county. These findings are in line with those of a Nigerian study reporting that high-level facilities, such as government-owned general/teaching hospitals, were the most commonly chosen in any childhood illness episode [39]. We found that household annual income was not the main factor in some circumstances, which is inconsistent with other studies in China [8,40]. Further, these findings are odds with studies in Brazil and Belgium, where income was one of the most significant determinants of healthcare utilization [41,42]. A previous study of migrants indicated that this group had a lower socioeconomic status than local residents [2]. In this study, migrant status did not play an important role in the choice of tertiary healthcare provider inside the county. However, the local children were more likely to choose the tertiary provider outside the county. In this study, migrant status did not play an important role in the choice of the tertiary healthcare provider inside the county. However, the local children were more likely to choose the tertiary provider outside the county. The present results may be owing to Kunshan's high economic level and diminishing differences between the local and migrant residents. As these are no longer important factors, the differences in choices may have been caused by the factors diminishing during the process of urbanization. The residents of Kunshan were less sensitive to health expenditures than those in less urbanized places. Significant differences existed in terms of the perception of different categories of institutions. It is worth noting that the responsiveness of the tertiary provider was lower than primary and secondary providers inside the county. In addition, in the comparison of the level-three institutions within the city and outside the city, two groups indicated that they were dissatisfied with the medical technology and medical facility inside the county compared with those of the tertiary outside the county. As well as giving a short-term lift to responsiveness [43], local governments should concentrate on the county provider's performance for the local government, especially tertiary facilities in the county. In the process of urbanization in other countries, especially in developing countries [44], the phenomena has appeared among a growing floating population. This brings challenges to the urban health service system, and the government may ignore the series of problems brought by this.

This study has some limitations. First, owing to the large floating population in Kunshan County and the lack of detailed information about said population, it is difficult to use random sampling to perform tests based on the total population. Thus, the study sample selected at the physical examination and planned immunization services sites were, to some extent, representative of older adults and children living in Kunshan, respectively, which may have influenced the reflection of the real situation. Second, this study mainly concentrated on residents' responses regarding their healthcare choices, which had some bias given their actual choices for treatment. Finally, as the study was only conducted in Kunshan, the generalizability of the results is limited. We will address these limitations in future studies. 


\section{Conclusions}

Compared with older adults, parents are more likely to prefer highest-level local facilities outside the county for their offspring, especially for younger children. It appears that parents lack confidence in primary healthcare, even when the child's illness is not serious. In addition, a substantial proportion of both older adults and parents preferred tertiary healthcare providers outside the county, owing to a lack of trust in their county counterparts' ability to manage serious diseases. A substantial proportion of residents chose to seek healthcare outside the county, which means that local healthcare providers were faced with potential health service challenges, especially pediatric health services. Based on these results, local governments should particularly seek to strengthen pediatric primary health services and improve the responsiveness of healthcare facilities to treat geriatric and pediatric diseases. Meanwhile, tertiary healthcare providers inside the county should be improved. It is especially important to improve the responsiveness and ability of tertiary healthcare providers to deal with complicated pediatric diseases.

Author Contributions: X.L. contributed to the conception and design of the study, with assistance from Y.Z., L.M. and J.L. Y.Z. and L.M. drafted the manuscript, while Q.Z., G.C., M.S. and F.C. contributed to the revision of the manuscript, and Y.Z. and L.M. finalized the manuscript. X.L., Y.Z. and L.M. contributed to the statistics and randomization. Y.Z. and L.M. contributed equally to this paper. All authors have read and agreed to the published version of the manuscript.

Funding: The project was supported by the National Natural Science Foundation of China (No. 71573049), the National Social Science Foundation of China (No.17ZDA078) and the 111 Project (Grant number B16031). The funders had no role in study design, data collection and analysis, decision to publish or preparation of the manuscript.

Acknowledgments: We are grateful to the staff at the community health service centers. We would also like to thank all the residents for their participation.

Conflicts of Interest: The authors declare no conflict of interest.

\section{References}

1. Li, H.; Dong, S. Measuring and Benchmarking Technical Efficiency of Public Hospitals in Tianjin, China: A Bootstrap-Data Envelopment Analysis Approach. Inquiry 2015, 52, 1-5. [CrossRef]

2. Sun, J.; Guo, Y.; Wang, X.N.; Zeng, Q. mHealth For Aging China: Opportunities and Challenges. Aging Dis. 2016, 7, 53-67. [CrossRef] [PubMed]

3. Sun, J.; Lin, Q.; Zhao, P.Y.; Zhang, Q.Y.; Xu, K.; Chen, H.Y.; Hu, C.; Stuntz, M.; Li, H.; Liu, Y.L. Reducing waiting time and raising outpatient satisfaction in a Chinese public tertiary general hospital-an interrupted time series study. BMC Public Health 2017, 17, 668-679. [PubMed]

4. Chao, J.Q.; Lu, B.Y.; Zhang, H.; Zhu, L.G.; Jin, H.; Liu, P. Healthcare system responsiveness in Jiangsu Province, China. BMC Health Serv. Res. 2017, 17, 31-38. [CrossRef] [PubMed]

5. Liu, T.Y.; Hao, X.N.; Zhang, Z.Z. Identifying community healthcare supports for the elderly and the factors affecting their aging care model preference: Evidence from three districts of Beijing. BMC Health Serv. Res. 2016, 16, 83-92. [CrossRef]

6. Yu, W.Y.; Li, M.; Nong, X.; Ding, T.; Ye, F.; Liu, J.Z.; Dai, Z.H.; Zhang, L.L. Practices and attitudes of doctors and patients to downward referral in Shanghai, China. BMJ Open 2017, 7, e012565. [CrossRef] [PubMed]

7. Yang, H.J.; Huang, X.; Zhou, Z.H.; Wang, H.H.X.; Tong, X.Y.; Wang, Z.H.; Wang, J.J.; Lu, Z.X. Determinants of Initial Utilization of Community Healthcare Services among Patients with Major Non-Communicable Chronic Diseases in South China. PLoS ONE 2014, 9, e116051. [CrossRef]

8. Yip, W.; Hsiao, W. Harnessing the privatisation of China's fragmented health-care delivery. Lancet 2014, 384, 805-818. [CrossRef]

9. General Office of the State Council of the People's Republic of China. Guidelines of the General Office of the State Council on the Comprehensive Reform of County-Level Public Hospitals 2015 (2015); General Office of the State Council of the People's Republic of China: Beijing, China, 2015. Available online: http: //www.gov.cn/zhengce/content/2015-05/08/content_9710.htm (accessed on 8 May 2015). 
10. Wang, Y.; Zhou, W.; Yu, R. The biggest lifestyle trends to watch. China Daily. Available online: http: //usa.chinadaily.com.cn/china/2016-01/02/content_22900357.htm (accessed on 1 February 2016).

11. Daily, C. China's Population Expected to Reach 1.45 bln by 2030. Available online: http://www.chinadaily. com.cn/china/2015-10/30/content_22329857.htm (accessed on 31 October 2015).

12. Feng, N. An Analysis of the reasons for the shrinking talent pool of pediatricians. Lab. Med. Clin. 2012, 9, 1660-1661.

13. Gong, P.; Liang, S.; Carlton, E.J.; Jiang, Q.W.; Remais, J.V. Urbanisation and health in China. Lancet 2012, 379, 843-852. [CrossRef]

14. Sturgeon, D. Convenience, quality and choice: Patient and service-provider perspectives for treating primary care complaints in urgent care settings. Int. Emerg. Nurs. 2017, 35, 43-50. [PubMed]

15. Rita, S.; Hugh, G.; Carol, P. Does Quality Affect Patients' Choice of Doctor? Evidence from England. Econ. J. 2016, 127, 445-494.

16. Jiang, F.G.; Glahn, T.V.; Chang, H.; Rogers, W.H.; Safran, D.G. Providing Patients Web-based Data to Inform Physician Choice: If You Build It, Will They Come? J. Gen. Intern. Med. 2007, 22, 1463-1466.

17. Hou, S.T.; Zhang, L.H.; Gan, Y.H. Analysis and Implications of the Factors Influencing Beijing Residents' Choice of Medical Services. Chin. J. Soc. Med. 2017, 34, 350-352.

18. Lewis, S.; Karen, W.; Fran, C. Navigating and making choices about healthcare: The role of place. Health Place 2018, 52, 215-220.

19. Geitona, M.; Zavras, D.; Kyriopoulos, J. Determinants of healthcare utilization in Greece: Implications for decision-making. Eur. J. Gen. Pract. 2009, 13, 144-150.

20. Yu, W.; Li, M.; Ye, F.; Xue, C.; Zhang, L.L. Patient preference and choice of healthcare providers in Shanghai, China: A cross-sectional study. BMJ Open 2017, 7, e016418. [CrossRef]

21. Wang, X.L. Research on the Strategy of Government Promoting the Transformation and Upgrading of County Economy-A Case Study of Zhucheng City, Shandong Province; Shangdong University: Jinan, China, 2015.

22. Tang, L.Y. The patient's anxiety before seeing a doctor and her his hospital choice behavior in China. BMC Public Health 2012, 12, 1121.

23. National Population and Family Planning Commission of Jiangsu Province. Provincial Health and Family Planning Commission on the Confirmation of Nanjing Gaochun People's Hospital and Five Other Hospitals as Tertiary Hospitals Notice 2018 (2018); National Population and Family Planning Commission of Jiangsu Province: Jiangsu, China, 2018. Available online: http://wjw.jiangsu.gov.cn/art/2018/2/13/art_49499_7488902.html (accessed on 13 February 2018).

24. National Population and Family Planning Commission of the People's Republic of China. Outline of the Healthy China 2030 Plan (2016); Guangming Daily: Beijing, China, 2016.

25. Liang, C.C. Research on Regional Disparity and Income Distribution Effect of Urban and Rural Minimum Living Security in China; Chinese Academy of Fiscal Sciences: Beijing, China, 2019.

26. Huo, Y.Y.; Ma, A.N.; Lu, J.; Chen, Q.L.; Zhang, D.; Xie, D.W.; Hao, F.F.; Wan, H.; Liu, B.S. Analysis of Current Situation and Problem of Health Personnel Allocation in Kunshan City. Med. Soc. 2017, 3, 5-8.

27. Center for Health Statistics and Information. Health Statistics Yearbook of China, 2017 (2017); Center for Health Statistics and Information: Beijing, China, 2017.

28. Jin, X. A Study on the Imbalance between Supply and Demand of Pediatric Medical Services in Eshan County; Yunnan University: Kunming, China, 2016.

29. Li, C.J.; Chen, L. Analysis on the causes and countermeasures of paediatrician shortage in China. J. Med. Theory Pract. 2017, 3, 2181-2183.

30. Harper, B.D.; Nganga, W.; Armstrong, R.; Forsyth, K.D.; Russ, C.M. Where are the paediatricians? An international survey to understand the global paediatric workforce. BMJ Paediatr. Open 2019, 3, e000397.

31. Bao, L.J. Study of Health Talent Competitiveness of the Four Municipalities in China; Tianjin Medical University: Tianjin, China, 2013.

32. Kang, X.L. Analysis on the Behavior of Wuhan Residents' Choice of Medical Institution and Its Influencing Factors; Central China Normal University: Wuhan, China, 2016.

33. Center for Health Statistics and Information. An Analysis Report of National Health Services Survey in China 2013 (2013); Center for Health Statistics and Information: Beijing, China, 2013. 
34. Center for Health Statistics and Information. Reports of Nation Health Service Survey Summary, 2004 (2004); Center for Health Statistics and Information: Beijing, China, 2004.

35. Ciccozzi, M.; Liu, Y.; Kong, Q.X.; Yuan, S.S.; Klunder, J.V.D. Factors influencing choice of health system access level in China: A systematic review. PLoS ONE 2018, 13, e0201887. [CrossRef]

36. Qian, W.J.; Huang, J.Y. Investigation on Utilization and Satisfaction of Medical Institutions at County Level: A Case from Yuhuan, Zhejiang. Chin. Prim. Health Care 2018, 32, 1-3. [CrossRef]

37. Zhou, Y.F.; Qian, D.F.; Xu, L.; Zhang, Y.G. Analysis on the trend of change of outpatients' characteristics in urban community health institutions. Chin. Health Resour. 2011, 14, 259-261.

38. Xu, S.Y.; Ming, J.; Xing, Y.; Gao, B.; Yang, C.B.; Ji, Q.H.; Chen, G. Regional differences in diabetes prevalence and awareness between coastal and interior provinces in China: A population-based cross-sectional study. BMC Public Heath 2013, 13, 299-306.

39. Oredola, A.S.; Odusanya, O.O. A Survey of the Perception of the Quality of and Preference of Healthcare Services amongst Residents of Abeokuta South Local Government, Ogun State, Nigeria. Niger. J. Clin. Pract. 2007, 20, 1088-1097.

40. Jin, C.; Cheng, J.Q.; Lu, Y.Q.; Huang, Z.F.; Cao, F.D. Spatial inequity in access to healthcare facilities at a county level in a developing country: A case study of Deqing County, Zhejiang, China. Int. J. Equity Health 2015, 14, 67. [CrossRef]

41. Travassos, C.; Viacava, F.; Pinheiro, R.; Brito, A. Utilization of health care services in Brazil: Gender, family characteristics and social status. Rev. Panam. Salud Publica 2000, 11, 365-373.

42. Van, J.H.A.; Demarest, S.; Tafforeau, J.; Van, H. Socio-economic differences in the utilisation of health services in Belgium. Health Policy 2003, 65, 153-165.

43. Rashidian, A.; Kavosi, Z.; Majdzadeh, R.; Pourreza, A.; Pourmalek, F.; Arab, M.; Mohammad, K. Assessing Health System Responsiveness: A Household Survey in 17th District of Tehran. Iran. Red Crescent Med. J. 2011, 13, 302-308.

44. Abu, M.; Codjoe, S. Experience and Future Perceived Risk of Floods and Diarrheal Disease in Urban Poor Communities in Accra, Ghana. Int. J. Environ. Res. Public Health 2018, 15, 2830-2846.

Publisher's Note: MDPI stays neutral with regard to jurisdictional claims in published maps and institutional affiliations.

(C) 2020 by the authors. Licensee MDPI, Basel, Switzerland. This article is an open access article distributed under the terms and conditions of the Creative Commons Attribution (CC BY) license (http://creativecommons.org/licenses/by/4.0/). 